\title{
Prognostic Influence of Internal Mammary Node Drainage in Patients with Early-stage Breast Cancer
}

\author{
LUCIE LUKESOVA ${ }^{1}$, DAVID VRANA ${ }^{1,2,3}$, IVAN SVACH ${ }^{4}$, NORA ZLAMALOVA ${ }^{4}$, \\ JIRI GATEK ${ }^{5,8}$, ZUZANA VLACHOVÁ $^{1}$, MARCEL MATZENAUER ${ }^{1}$, \\ PAVEL KORANDA ${ }^{6}$, KLARA HRUZOVA $^{1}$, TOMAS TICHY ${ }^{7}$ and BOHUSLAV MELICHAR ${ }^{1,2}$ \\ Departments of ${ }^{1}$ Oncology, ${ }^{4}$ Surgery I, ${ }^{6}$ Nuclear Medicine, ${ }^{7}$ Department of Clinical and Molecular Pathology and \\ ${ }^{2}$ Institute of Molecular and Translational Medicine Faculty of Medicine and Dentistry, \\ Palacky University, Olomouc, Czech Republic; \\ ${ }^{3}$ Toxicogenomics Unit, National Institute of Public Health, Prague, Czech Republic; \\ ${ }^{5}$ Department of Surgery, Atlas Hospital, Zlín, Czech Republic; \\ ${ }^{8}$ Faculty of Humanities, Tomas Bata University in Zlín, Zlin Czech Republic
}

\begin{abstract}
Background: The management of internal mammary nodes (IMNs) during multidisciplinary treatment of breast cancer has been debated for the last four decades without unequivocal conclusion. Patients and Methods: We retrospectively reviewed patients with breast cancer who underwent sentinel lymph node biopsy at our center from 2008 until 2012. IMN drainage was assessed as a potential risk factor for local and distant disease recurrence. Results: We identified 712 patients, with incidence of drainage to IMNs of 18.4\%. No detrimental effect of the pattern of drainage to IMNs was found after a median follow-up of 58 months. A similar outcome was observed when drainage to IMNs was evaluated as a risk factor for patient survival. The potential risk factors for drainage to IMNs during sentinel lymph node biopsy were younger age $(p=0.002)$ and tumor location in lower-outer, lower-inner, and upper-inner versus upper-outer quadrant $(p<0.0001)$. Conclusion: The drainage to IMNs is unlikely to have a detrimental effect on patient outcome.
\end{abstract}

Breast cancer is the most common cancer among women worldwide. Over the last 100 years considerable progress has been made in surgical management of early-stage breast cancer. The strategy of breast cancer management is inseparably connected with treatment of regional lymph nodes including axillary, internal mammary, supraclaviculary and intramammary nodes. Veronesi et al. published a trial in 1999 with 30 years of

Correspondence to: Dr. David Vrána, Ph.D., Department of Oncology, Faculty of Medicine and Dentistry, Palacky University, Olomouc, Czech Republic. Tel: +420 588444295, Fax: +420 588444295, e-mail: davvrana@gmail.com.

Key Words: Breast cancer, lymph nodes, radiotherapy, internal mammary nodes, drainage. follow-up investigating the effect of including resection of internal mammary nodes (IMNs) in breast cancer surgery (1). This trial confirmed that the omission of resection of IMNs does not compromise patient outcome. The approach to axillary lymph nodes in early-stage breast cancer management is quite straightforward based on robust data from clinical trials which clearly shift towards less radical treatment. Extensive local treatment seems to have little effect on patient oncological outcome but significantly increases morbidity and the cost of treatment (2-9). Unfortunately, the situation for drainage of IMNs may be viewed differently. This group of nodes located along the internal mammary artery is frequently visualized during the sentinel lymph node biopsy (SLNB), but there is no unequivocal guideline as to how to manage these cases during breast cancer surgery. Biopsy of IMNs may expose patients to additional operative risk and significantly prolongs the duration of the surgical procedure, and, consequently, increases the cost of the surgery. Imaging studies are generally useless due to the fact that these lymph nodes would have to double or triple their size in order to be visualized on computed tomography (CT), or magnetic resonance imaging, except for positron-emission tomography, which can potentially display even non-enlarged lymph nodes. Interestingly, even considering the fact that this problem has been investigated for over 40 years, and many articles have been published, no clear conclusion has been made so far, and conflicting results continue to be reported (10). The clinical practice differs significantly from one center to another, ranging from avoiding any procedure for this group of lymph nodes, regardless of whether these are visualized during the SLNB, to surgical biopsy or radiotherapy of IMNs in all patients. Presence of metastases in the IMNs significantly changes the staging of disease but the impact on patient outcome is unknown, and it is possible that new systemic treatments will offset the uncertainties in local staging and treatment. 
The aim of the present study was to investigate if drainage to IMNs is a negative prognostic factor for patients with breast cancer.

\section{Patients and Methods}

In the present study, patients with breast cancer without evidence of distant metastases at the time of diagnosis treated at the University Hospital Olomouc between 2008 and 2012 with SLNB were retrospectively reviewed. The SLNB was introduced into clinical practice at our center in 2008 and all patients treated through 2012 were analyzed (to obtain approximately a 5-year median follow-up). According to standards at our center, SLNB is utilized for all patients with non-metastatic breast cancer without clinically evident axillary lymphadenopathy. Distant metastases were excluded by chest- $X$ ray, abdominal ultrasound and bone scan. Pathological data included tumor histology, TNM staging, tumor location in the breast, human epidermal growth factor receptor 2 (HER2) expression, hormonal status [estrogen (ER) and progesterone (PR) receptor positivity, considering $\geq 1 \%$ as a cutoff for hormonal positivity], Ki-67 proliferative index and grading. Data regarding local and distant recurrences together with the survival data were collected. The patients were stratified according to their age at diagnosis as being under 60 or $\geq 60$ years of age. Based on the tumor phenotype, patients were also stratified into four groups as: luminal A: tumors with expression of hormone receptors, HER2-negative, with low Ki-67 and high PR expression; luminal B: HER2-negative, low expression of PR (with $20 \%$ cut-off), or high Ki-67 (with $20 \%$ cutoff), or HER2-positive with expression of hormonal receptors; triplenegative: HER2-negative, without expression of hormonal receptors; and HER2 non-luminal: HER2-positive without expression of hormonal receptors; as recommended by the European Society for Medical Oncology Clinical Practice Guidelines (11).

The SLNB procedure was generally performed at our center utilizing 99mTc-nanocolloid (Nanocoll; GE Healthcare, Milan, Italy) with albumin particles smaller than $80 \mathrm{~nm}$ with $300 \mathrm{MBq}$ activity. Peritumoral injection of radiocolloid one day before the surgical procedure was used as a standard. Subdermal or retroreolar administration of the radiocolloid was used only in the case of absent or faint scintigraphic imaging of the SLN. Lymphoscintigraphy (e.cam gamma camera; Siemens, Erlangen, Germany) followed 5-40 minutes and 60-80 minutes after radiocolloid application. Planar scintigrams in anterior, oblique and lateral view were acquired, single photonemission CT/low-dose CT was completed if needed (mainly due to abnormal SLN localization). Localization of the SLN was marked on the skin in the anterior and lateral projections to facilitate the biopsy procedure. During the surgery, the exact SLN was confirmed with gamma probe (Neoprobe GDS; Gamma Detection System, Dublin, $\mathrm{OH}$, USA). Patentblue was not used for SLNB identification purposes.

The association between clinical parameters and drainage to IMNs was studied using the Chi-square test for categorical variables and two-sided Wilcoxon rank-sum test for age as a continuous variable. Subsequently, parameters with a $p$-value lower than 0.5 were included in logistic regression to find the predictors of IMN drainage. Next, the survival analysis was performed. In univariate analysis, the log-rank test was used to find the risk factors for overall (OS) and disease free survival (DFS) measured from the time of surgery to disease relapse. From the log-rank test, the factors with a $p$-value lower than 0.5 were chosen for inclusion in the Cox multivariate regression. From these risk factors, the algorithm chose to present only those that were significant to be presented in a more detail (HR, 95\% CI, $p$-value).
Statistical analyses were performed using SAS/STAT ${ }^{\circledR} 9.3$ software (SAS Institute Inc., Cary, NC, USA) and the decision on statistical significance was based on a level of $p=0.05$.

\section{Results}

In total, 712 patients were included in this retrospective analysis, including $131(18.4 \%)$ patients who had IMNs detected during the SLNB procedure. None of the patients underwent IMN biopsy to confirm or exclude the presence of IMN metastases. After a median follow-up of 58 months there were seven local recurrences, 43 patients had metastatic disease and 31 patients had died. Diagnosis with another primary tumor (seven patients) during the follow-up period, conclusively identified as different from first primary breast cancer, was not considered as disease recurrence for the purpose of this study.

The clinical and pathological parameters as risk factors for drainage to IMNs are summarized in Table I. The only potential factors associated with drainage to IMNs were age as a continuous variable and the location of the tumor in the lower-outer, lower-inner or upper-inner quadrant (Table II). The risk for local or distant recurrence was not related to the drainage and IMN visualization during the SLNB (Table III). Increasing age $(p=0.0001)$ and HER 2 negativity $(p=0.0412)$ correlated with better OS, but drainage to IMNs was not identified as a risk factor for OS $(p=0.4055)$ (Table IV). Age $(p=0.0071)$ was identified as potential risk factor for disease recurrence (local or distant). Tumor location, grade, hormone receptor expression, tumor $\mathrm{T}$ staging, nodal status, histological type, HER2 and prognostic subgroups were not found to be risk factors of DFS. The present data did not show a role of IMN drainage as a risk factor for disease recurrence $(p=0.7684)$. The summary of risk factors for disease recurrence is given in Table $\mathrm{V}$.

\section{Discussion}

In the present analysis, tumor location and age were associated with drainage to IMNs, but IMN drainage had no effect on recurrence rate or OS.

Even after decades of research, the optimal management of IMN in breast cancer remains unknown. Radiotherapy, IMN biopsy or extensive imaging techniques seem to be unsuitable for all patients with breast cancer. Selection of subgroup of patients for possible further management of IMNs may be more appropriate in order to avoid morbidity from IMN biopsy during the primary surgical procedure and toxicity of IMN radiotherapy in the majority of patients. The latter is important especially in the case of left-sided breast cancer, where IMN radiotherapy is performed utilizing separate electron field or tilting the photon tangential field, which can significantly increase the heart dose and likelihood of long-term heart toxicity. Radiotherapy-induced heart morbidity can, thereby, 
Table I. Patient and tumor characteristics as a risk factor for drainage to internal mammary nodes (IMNs).

\begin{tabular}{|c|c|c|c|c|}
\hline Characteristic & Total & IMN drainage & No IMN drainage & $p$-Value \\
\hline Number of patients & 712 & 131 & 581 & \\
\hline \multicolumn{5}{|l|}{ Age, years } \\
\hline Mean & 60 & 57 & 60 & \multirow[t]{3}{*}{0.0020} \\
\hline Median & 60 & 58 & 61 & \\
\hline Range & $20-86$ & $20-81$ & $25-86$ & \\
\hline \multicolumn{5}{|l|}{ ER expression, n (\%) } \\
\hline Positive & $598(84.1)$ & $107(81.68)$ & $491(84.66)$ & \multirow[t]{2}{*}{0.4001} \\
\hline Negative & $113(15.89)$ & $24(18.32)$ & $89(15.34)$ & \\
\hline Missing data & 1 & & & \\
\hline \multicolumn{5}{|l|}{ PR expression, $\mathrm{n}(\%)$} \\
\hline Positive & $482(67.79)$ & $83(63.36)$ & $399(68.79)$ & \multirow[t]{2}{*}{0.2293} \\
\hline Negative & $229(32.21)$ & $48(36.64)$ & $181(31.21)$ & \\
\hline Missing data & 1 & & & \\
\hline \multicolumn{5}{|l|}{ Tumor location, n (\%) } \\
\hline Central & $58(8.2 \%)$ & $10(7.63)$ & $48(8.28)$ & \multirow[t]{5}{*}{$<0.0001$} \\
\hline UIQ & $102(14.3 \%)$ & $25(19.08)$ & $77(13.28)$ & \\
\hline UOQ & $458(64.4 \%)$ & $65(49.62)$ & $393(67.76)$ & \\
\hline LIQ & $70(9.8 \%)$ & $20(15.27)$ & $50(8.62)$ & \\
\hline LOQ & $23(3.2 \%)$ & $11(8.40)$ & $12(2.07)$ & \\
\hline \multicolumn{5}{|l|}{$\mathrm{T}$ Classification, $\mathrm{n}(\%)$} \\
\hline TIS & $115(16.2)$ & $23(17.56)$ & $92(15.83)$ & \multirow[t]{5}{*}{0.8554} \\
\hline 1 & $487(68.4)$ & $89(67.94)$ & $398(68.5)$ & \\
\hline 2 & $105(14.7)$ & $19(14.5)$ & $86(14.8)$ & \\
\hline 3 & $3(0.4)$ & 0 & $3(0.52)$ & \\
\hline 4 & $2(0.3)$ & 0 & $2(0.34)$ & \\
\hline \multicolumn{5}{|l|}{ Nodal status, n (\%) } \\
\hline Positive & $115(16.2)$ & $22(16.79)$ & $93(16.01)$ & \multirow[t]{2}{*}{0.8250} \\
\hline Negative & $597(83.8)$ & $109(83.21)$ & 488 (83.99) & \\
\hline \multicolumn{5}{|l|}{ Histology, n (\%) } \\
\hline DCIS & $111(15.6)$ & $24(18.32)$ & 87 (14.97) & \multirow[t]{5}{*}{0.7865} \\
\hline LCIS & $3(0.4)$ & $1(0.76)$ & $2(0.34)$ & \\
\hline Ductal invasive & $534(75)$ & $93(70.99)$ & $441(75.9)$ & \\
\hline Lobular invasive & $45(6.3)$ & $9(6.87)$ & $36(6.2)$ & \\
\hline Other & $19(2.7)$ & $4(3.05)$ & $15(2.58)$ & \\
\hline \multicolumn{5}{|l|}{ HER2 status, n (\%) } \\
\hline Positive & $113(15.9)$ & $21(16.03)$ & $92(15.86)$ & \multirow[t]{2}{*}{0.9620} \\
\hline Negative & $598(84.1)$ & $110(83.97)$ & $488(84.14)$ & \\
\hline \multicolumn{5}{|l|}{ Grading } \\
\hline 1 & $170(23.9)$ & $34(25.95)$ & $136(23.41)$ & \multirow[t]{3}{*}{0.7565} \\
\hline 2 & $384(53.9)$ & $67(51.15)$ & $317(54.56)$ & \\
\hline 3 & $158(22.2)$ & $30(22.9)$ & $128(22.03)$ & \\
\hline \multicolumn{5}{|l|}{ Prognostic subgroups } \\
\hline Luminal A & $328(46.1)$ & $55(41.98)$ & $273(46.99)$ & \multirow[t]{5}{*}{0.7804} \\
\hline Luminal B, HER2- & $202(28.4)$ & $39(29.77)$ & $163(28.06)$ & \\
\hline Luminal B, HER2+ & $69(9.7)$ & $13(9.92)$ & $56(9.64)$ & \\
\hline HER2+, non-luminal & $44(6.2)$ & $8(6.11)$ & $36(6.20)$ & \\
\hline Triple-negative & $69(9.7)$ & $16(12.21)$ & $53(9.12)$ & \\
\hline
\end{tabular}

UIQ: Upper-inner quadrant, UOQ: upper-outer quadrant, LIQ: lower-inner quadrant, LOQ: lower-outer quadrant, DCIS: ductal carcinoma in situ, LCIS: lobular carcinoma in situ, ER: estrogen receptor, PR: progesterone receptor, HER2: human epidermal growth factor receptor 2, TIS: tumor in situ.

offset the benefit of radiotherapy and, considering the expected long-term survival of patients with early-stage breast cancer, can jeopardize the survival of patients even more than breast cancer itself (12).

The published incidence of drainage to IMNs during SLNB ranges between $9 \%$ and $44 \%(13,14)$, which our findings
(18.4\%) correspond with. This wide range is caused by differences in the tracer used (Patentblue or radiocolloid) and the site of application (intratumoral, peritumoral, or subcutaneus). Several authors tried to identify the potential risk factors for drainage to IMNs and the presence of IMN metastasis during SLNB procedure. We previously presented a 
Table II. Logistic regression of statistically significant predictors of drainage to internal mammary nodes.

\begin{tabular}{lcccc}
\hline Factor & OR & \multicolumn{2}{c}{$95 \%$ CI } & $p$-Value \\
\hline Age $^{\mathrm{a}}$ & 0.971 & 0.954 & 0.989 & 0.0013 \\
Tumor location & & & & $<0.0001$ \\
$\quad$ LOQ $v s$. UOQ & 5.684 & 2.382 & 13.567 & $<0.0001$ \\
LIQ $v$ s. UOQ & 2.624 & 1.454 & 4.735 & 0.0014 \\
UIQ vs. UOQ & 2.026 & 1.195 & 3.435 & 0.0088 \\
Central vs. UOQ & 1.319 & 0.633 & 2.751 & 0.46 \\
\hline
\end{tabular}

UIQ: Upper-inner quadrant, UOQ: upper-outer quadrant, LIQ: lowerinner quadrant, LOQ: lower-outer quadrant, DCIS: ductal carcinoma in situ, LCIS: lobular carcinoma in situ, OR: odds ratio, CI: confidence interval. aAs continuous variable.

report describing potential risk factors for drainage to IMNs, postulating that the drainage to IMNs should be a risk factor for IMN metastasis and the combination of such risk factors could potentially indicate a subgroup of patients suitable for biopsy or radiotherapy. Six risk factors for drainage to IMNs were identified including age younger than 50 years, location of the cancer in central and medial quadrants, HER2 overexpression, expression of progesterone receptors, tumor size over $2 \mathrm{~cm}$ and metastasis to axillary lymph nodes (15). Hindie et al. reported axillary lymph node positivity and drainage to IMNs as risk factors for the presence of metastasis in IMNs (16). In the present study, we included all patients with SLNB from 2008 until 2012, in order to avoid any selection bias (which could be criticized in our previous paper) and at the same time reaching a median follow-up of almost 5 years, providing data regarding disease (local and distant) recurrence and also some preliminary survival data. When the studied group of patients was expanded to include all patients undergoing SLNB, the statistically significant differences observed in prior studies disappeared. We found age and location of the tumor in the left outer quadrant, left inner quadrant and upper inner quadrant to be statistically significant predictors for drainage to IMNs.

At the same time there was a question raised as to whether the lymph drainage to IMNs might be a negative prognostic factor for patient outcome. The present analysis after 58 months of median follow-up did not show any statistically significant differences in the patient outcome regardless of local or distant recurrence, or OS. These results are contrary to the report presented by Kong et al. assessing 1,772 patients with breast cancer, of whom 334 patients had drainage to IMNs during SLNB. IMN drainage correlated with worse DFS (17). On the other hand Koo et al., after reviewing 525 patients with breast cancer, did not demonstrate any detrimental effect of drainage to IMNs (18).

One possible explanation for differences in local and especially distant recurrence may be the efficacy of systemic
Table III. Drainage to internal mammary nodes (IMNs) as a potential risk factor for local and distant recurrence, and overall survival.

\begin{tabular}{lccc}
\hline & $\begin{array}{c}\text { IMN drainage } \\
\mathrm{n}(\%)\end{array}$ & $\begin{array}{c}\text { No IMN drainage } \\
\mathrm{n}(\%)\end{array}$ & $p$-Value \\
& & & \\
\hline $\begin{array}{l}\text { Distant recurrence } \\
\text { Yes }\end{array}$ & $9(6.87)$ & $34(5.85)$ & 0.6585 \\
$\quad$ No & $122(93.13)$ & $547(94.15)$ & \\
Local recurrence & & & \\
$\quad$ Yes & $1(0.76)$ & $6(1.03)$ & 0.7778 \\
$\quad$ No & $130(99.24)$ & $575(98.97)$ & \\
$\begin{array}{l}\text { Overall survival } \\
\text { Alive }\end{array}$ & $127(96.95)$ & $554(95.35)$ & 0.4194 \\
$\quad$ Dead & $4(3.05)$ & $27(4.65)$ & \\
\hline
\end{tabular}

treatment and differences in its use among different institutions. Rapidly emerging new systemic treatment options which were not included in older trials before the introduction of, for example, trastuzumab (antibody to HER2 receptor) into daily clinical practice, can compensate for uncertainties in IMN management. It seems that lymph node drainage is not the appropriate factor by which to select a subgroup of patients with higher risk of disease recurrence; at the same time, drainage to IMNs most probably does not worsen a patient's outcome. Several studies have investigated whether radiotherapy to IMNs regardless of lymph drainage can improve DFS and OS. Fowble et al. found no difference in DFS and OS (19) and a similar outcome was presented by Olson et al. (20).

A recently published large Danish trial once again opened the old question regarding the potential significance of IMNs. The study assessed 3,089 patients with breast cancer with axillary lymph node metastases, and the authors cleverly bypassed the main potential side-effect of radiotherapy, namely cardiac toxicity. The study randomized patients to IMN radiotherapy or no-radiotherapy group based on the side of disease: Patients with left-sided breast cancer were included in the group without radiotherapy and those with right-sided disease in the group treated with radiotherapy. The trial confirmed the survival advantage of IMN irradiation (21). Axillary lymph node positivity seems to be a better predictor of patient suitability for IMN radiotherapy than lymph node drainage, however, long-term radiotherapy toxicity has to be taken into account when considering any radiotherapy for patients with breast cancer in whom long-term survival is expected.

Again, a main disadvantage of the present study was the lack of IMN biopsy to confirm the possible risk factors for IMN metastasis since IMN biopsy is not routinely performed at our institution regardless of the drainage pattern during SLNB. Our contemporary practice regarding IMN management is to avoid biopsy as well as radiotherapy of this node chain 
Table IV. Risk factors associated with overall survival.

\begin{tabular}{|c|c|c|c|c|}
\hline \multirow[t]{2}{*}{ Factor } & \multirow{2}{*}{$\begin{array}{c}\text { Log-rank test } \\
\text { p-Value }\end{array}$} & \multicolumn{3}{|c|}{ Cox regression } \\
\hline & & HR & $95 \% \mathrm{CI}$ & $p$-Value \\
\hline Age & $0.0048^{\mathrm{a}}$ & 1.076 & $1.036-1.116$ & $0.0001^{\mathrm{b}}$ \\
\hline IMN drainage (present, absent) & 0.4055 & & & \\
\hline Tumor location (central, UIQ, UOQ, LIQ, LOQ) & 0.1089 & & & \\
\hline Grade $(1,2,3)$ & 0.9120 & & & \\
\hline ER expression (positive, negative) & 0.6085 & & & \\
\hline PR expression (positive, negative) & 0.4573 & & & \\
\hline T Classificaton (TIS, T1, T2, T3, T4) & 0.0572 & & & \\
\hline Nodal status (positive, negative) & 0.1528 & & & \\
\hline HER2 (pozitive, negative) & 0.1685 & 0.409 & & \\
\hline $0.173-0.965$ & 0.0412 & & & \\
\hline Prognostic subgroups (Luminal A, Luminal B, Triple negative, Her2-non-luminal) & 0.7337 & & & \\
\hline Histology (DCIS, LCIS, ductal invasive, lobular invasive, other) & 0.2173 & & & \\
\hline
\end{tabular}

IMN: Internal mammary nodes, HR: hazard ratio, CI: confidence interval, ER: estrogen receptor, PR: progesterone receptor, HER2: human epidermal growth factor receptor 2 . ${ }^{\mathrm{a}}<60 / \geq 60$ years; as continuous variable.

Table V. Risk factors for disease recurrence.

\begin{tabular}{|c|c|c|c|c|}
\hline \multirow[t]{2}{*}{ Factor } & \multirow{2}{*}{$\begin{array}{c}\text { Log-rank test } \\
\text { p-Value }\end{array}$} & \multicolumn{3}{|c|}{ Cox regression } \\
\hline & & HR & $95 \% \mathrm{CI}$ & $p$-Value \\
\hline Age & $0.3806^{\mathrm{a}}$ & 1.039 & $1.01-1.068$ & $0.0071^{\mathrm{b}}$ \\
\hline IMN drainage (present, absent) & 0.7684 & & & \\
\hline Tumor location (central, UIQ, UOQ, LIQ, LOQ) & 0.3190 & & & \\
\hline Grade $(1,2,3)$ & 0.1384 & & & \\
\hline ER expression (positive, negative) & 0.0886 & & & \\
\hline PR expression (positive, negative) & 0.0362 & & & \\
\hline T Classification (TIS, T1, T2, T3, T4) & 0.0029 & & & \\
\hline Nodal status (pozitive, negative) & 0.8499 & & & \\
\hline HER2 (pozitive, negative) & 0.2621 & & & \\
\hline Prognostic subgroups (Luminal A, Luminal B, Triple negative, Her2-non-luminal) & 0.4182 & & & \\
\hline Histology (DCIS, LCIS, ductal invasive, lobular invasive, other) & 0.2582 & & & \\
\hline
\end{tabular}

IMN: Internal mammary nodes, HR: hazard ratio, CI: confidence interval, ER: estrogen receptor, PR: progesterone receptor, HER2: human epidermal growth factor receptor 2 . $^{\mathrm{a}}<60 / \geq 60$ years; $\mathrm{b}_{\text {as }}$ continuous variable.

regardless of the IMN visualization during SLNB. The only undisputed indication for IMN radiotherapy/biopsy are clinically-enlarged IMNs . We do not believe there is sufficient evidence that drainage to IMNs has a significant impact on patient outcome as the morbidity of the IMN biopsy or radiotherapy could outweigh its potential benefit.

The main advantage of our study compared to publications evaluating historical cohorts of patients is the fact that it included treatment with novel systemic modalities such as trastuzumab, which has a proven significant effect on patient outcome in the adjuvant setting and, due to the fact that this drug has been introduced into daily practice relatively recently, this benefit may not be seen in older studies.
The present retrospective study has obvious limitations. Although the median follow-up duration was close to 5 years, the data may still be regarded as immature because of the low number of events. Thus, the results may still be regarded as preliminary. Different breast cancer subtypes in fact represent different disorders, and after splitting the patients into subgroups, the number of patients may be too low to detect an association.

In conclusion, lymphatic drainage to IMNs detected during SLNB is not a negative prognostic factor in patients with early breast cancer. The strategy of management of patients with breast cancer should not be guided by the drainage pattern observed during SLNB. 


\section{Conflicts of Interest}

The Authors declare they have no conflict of interest in regard to this study.

\section{Acknowledgements}

This research was supported by Grant Project LO1304.

\section{References}

1 Veronesi U, Marubini E, Mariani L, Valagussa P and Zucali R: The dissection of internal mammary nodes does not improve the survival of breast cancer patients. 30-year results of a randomised trial. Eur J Cancer 35: 1320-1325, 1999.

2 Fisher B, Anderson S, Bryant J, Margolese RG, Deutsch M, Fisher ER, Jeong JH and Wolmark N: Twenty-year follow-up of a randomized trial comparing total mastectomy, lumpectomy, and lumpectomy plus irradiation for the treatment of invasive breast cancer. N Engl J Med 347: 1233-1241, 2002.

3 Vrana D, Gatek J, Lukesova L, Vazan T, Melichar B, Pospiskova $\mathrm{M}$ and Svach I: Omission of adjuvant radiation therapy in elderly patients with low risk breast cancer undergoing breast-conserving surgery - two center experience. Biomed Pap Med Fac Univ Palacky Olomouc Czech Repub 158: 461-464, 2014.

4 Gatek J, Vrana D, Melichar B, Vazan P, Kotocova K, Kotoc J, Dudesek B, Hnatek L and Duben J: Significance of the resection margin and risk factors for close or positive resection margin in patients undergoing breast-conserving surgery. J BUON 17: 452456, 2012.

5 Krag DN, Anderson SJ, Julian TB, Brown AM, Harlow SP, Costantino JP, Ashikaga T, Weaver DL, Mamounas EP, Jalovec LM, Frazier TG, Noyes RD, Robidoux A, Scarth HM and Wolmark N: Sentinel-lymph-node resection compared with conventional axillary-lymph-node dissection in clinically node-negative patients with breast cancer: overall survival findings from the NSABP B-32 randomised phase 3 trial. Lancet Oncol 11: 927-933, 2010.

6 Gatek J, Vrana D, Hnatek L, Bakala J, Dudesek B, Duben J and Musil T: Node biopsy and neoadjuvant chemotherapy in the treatment of breast cancer. J BUON 17: 265-270, 2012.

7 Giuliano AE, Hunt KK, Ballman KV, Beitsch PD, Whitworth PW, Blumencranz PW, Leitch AM, Saha S, McCall LM and Morrow M: Axillary dissection vs. no axillary dissection in women with invasive breast cancer and sentinel node metastasis: a randomized clinical trial. JAMA 305: 569-575, 2011.

8 Donker M, van Tienhoven G, Straver ME, Meijnen P, van de Velde CJ,Mansel RE, Cataliotti L, Westenberg AH, Klinkenbijl JH, Orzalesi L, Bouma WH, van der Mijle HC, Nieuwenhuijzen GA, Veltkamp SC, Slaets L, Duez NJ, de Graaf PW, van Dalen T, Marinelli A, Rijna H, Snoj M, Bundred NJ, Merkus JW, Belkacemi Y, Petignat P, Schinagl DA, Coens C, Messina CG, Bogaerts J and Rutgers EJ: Radiotherapy or surgery of the axilla after a positive sentinel node in breast cancer (EORTC 10981-22023 AMAROS): a randomised, multicentre, open-label, phase 3 non-inferiority trial. Lancet Oncol 15: 1303-1310, 2014.

9 Krsička P, Coufal O and Zapletal O: Positive sentinel node in breast cancer - when and why also opt for axillary dissection?. Rozhl Chir 92: 684-689, 2013 (in Czech).

10 Vrana D, Gatek J, Cwiertka K, Lukesova L and Koranda P: Internal mammary node management in breast cancer. A review.
Biomed Pap Med Fac Univ Palacky Olomouc Czech Repub 157: 261-265, 2013.

11 Senkus E, Kyriakides S, Ohno S, Penault-Llorca F, Poortmans P, Rutgers E, Zackrisson $\mathrm{S}$ and Cardoso F: ESMO Guidelines Committee. Primary breast cancer: ESMO Clinical Practice Guidelines for diagnosis, treatment and follow-up. Ann Oncol 26: v8-30, 2015.

12 Clarke M, Collins R, Darby S, Davies C, Elphinstone P, Evans V, Godwin J, Gray R, Hicks C, James S, MacKinnon E, McGale P, McHugh T, Peto R, Taylor C and Wang Y: Early Breast Cancer Trialists' Collaborative Group (EBCTCG). Effects of radiotherapy and of differences in the extent of surgery for early breast cancer on local recurrence and 15-year survival: an overview of the randomised trials. Lancet 366: 2087-2106, 2005.

13 Domènech-Vilardell A, Bajén MT, Benítez AM, Ricart Y, Mora J, Rodríguez-Bel L, García-Tejedor A, Climent J, López-Ojeda A, Urruticoechea A and Martín-Comín J: Removal of the internal mammary sentinel node in breast cancer. Nucl Med Commun 30: 962-970, 2009.

14 Uren RF, Howman-Giles R, Renwick SB and Gillett D: Lymphatic mapping of the breast: locating the sentinel lymph nodes. World $\mathrm{J}$ Surg 25: 789-793, 2001.

15 Lukesova L, Vrana D, Gatek J, Koranda P, Cwiertka K, Radova L, Melichar B, Prouzova Z, Sramek V and Svach I: Predictive parameters for internal mammary node drainage in patients with early breast cancer. Tumori 100: 254-258, 2014.

16 Hindié E, Groheux D, Hennequin C, Zanotti-Fregonara P, Vercellino L, Berenger N, Toubert ME, Maylin C, Vilcoq JR and Espié M: Lymphoscintigraphy can select breast cancer patients for internal mammary chain radiotherapy. Int J Radiat Oncol Biol Phys 83: 1081-1088, 2012.

17 Kong AL, Tereffe W, Hunt KK, Yi M, Kang T, Weatherspoon K, Mitten- dorf EA, Bedrosian I, Hwang RF, Babiera GV, Buchholz TA and Meric-Bernstam F: Impact of internal mammary lymph node drainage identified by preoperative lymphoscintigraphy on outcomes in patients with stage I to III breast cancer. Cancer 118: 6287-6296, 2012.

18 Koo MY, Lee SK, Bae SY, Choi MY, Cho DH, Kim S, Lee JE, Nam SJ and Yang JH: Long-term outcome of internal mammary lymph node detected by lymphoscintigraphy in early breast cancer. J Breast Cancer 15: 98-104, 2012.

19 Fowble B, Hanlon A, Freedman G, Nicolaou N, Hoffman J, Sigurdson E, Boraas M, Torosian M and Goldstein L: Internal mammary node irradiation neither decreases distant metastases nor improves survival in stage I and II breast cancer. Int J Radiat Oncol Biol Phys 47: 883-894, 2000.

20 Olson RA, Woods R, Speers C, Lau J, Lo A, Truong PT, Tyldesley $\mathrm{S}$, Olivotto IA and Weir L: Does the intent to irradiate the internal mammary nodes impact survival in women with breast cancer? A population- based analysis in British Columbia. Int J Radiat Oncol Biol Phys 83: 35-41, 2012.

21 Thorsen LB, Offersen BV, Danø H, Berg M, Jensen I, Pedersen AN, Zimmermann SJ, Brodersen HJ, Overgaard $\mathrm{M}$ and Overgaard J: DBCG-IMN: A Population-Based Cohort Study on the Effect of Internal Mammary Node Irradiation in Early Node-Positive Breast Cancer. J Clin Oncol 34: 314-20, 2016.

Received October 28, 2016

Revised November 14, 2016

Accepted November 15, 2016 